\title{
Perbandingan Metode SAW dan Profile Matching Pada Pemilihan Rumah Tinggal Studi Kasus: Perumahan Depok
}

\author{
Comparison of SAW and Profile Matching Methods for Home Selection \\ Case Study: Depok Housing \\ ${ }^{1}$ Sunarti, ${ }^{2}$ Jenie Sundari \\ ${ }^{1}$ Manajemen Informatika, AMIK BSI Jakarta, ${ }^{2}$ Teknik Informatika,STMIK Nusa \\ Mandiri Jakarta \\ ${ }^{1,2}$ Jakarta, Indonesia \\ E-mail: ${ }^{1}$ sunarti.sni@bsi.ac.id, ${ }^{2}$ jenie.jni@ nusamandiri.ac.id
}

Abstrak - Tempat yang nyaman, strategis, sejuk dan harga terjangkau merupakan impian setiap orang untuk dijadikan rumah tinggal. Pada penelitian ini dilakukan pada perumahan diwilayah kota Depok dengan nama perumahan Grand Depok City, Telaga Kahuripan, Maharaja, Sawangan Permai dan Pesona Kayangan dengan menggunakan kriteria harga, lokasi, KPR, fasilitas, type rumah dan pembayaran awal dengan melakukan perbandingan dua metode Sitem pendukung Keputusan yaitu SAW dan Profile Matching. Metode tersebut merupakan metode yang hasil akhirnya berupa perengkingan dari proses perhitungan. Hasil perbandingan dari kedua metode adalah menghasilkan alternatif terpilih yang sama, sehingga kedua metode tersebut dapat diterapkan untuk membantu pengambilan keputusan dalam pemilihan rumah diwilayah kota Depok.

Kata Kunci-SAW, Profile Matching, Rumah Tinggal

Abstract-Convenient place, strategic, cool and affordable price is the dream of every person to be home. This research is conducted on housing in Depok City area with the name of Grand Depok City, Telaga Kahuripan, Maharaja, Sawangan Permai and Pesona Kayangan by using price, location, mortgage, facility, house type and initial payment by comparing two methods Supporting system of decision namely SAW and Profile Matching. The method is a method that the end result of the formation of the calculation process. The results of the comparison of the two methods are to produce the same chosen alternative, so that both methods can be applied to assist decision making in house selection in Depok.

Keywords-SAW, Profile Matching, Home Stay 
INTENSIF, Vol.2 No.2 August 2018

ISSN: 2580-409X (Print) / 2549-6824 (Online)

Website: http//ojs.unpkediri.ac.id/index.php/intensif

\section{PENDAHULUAN}

Rumah merupakan suatu kebutuhan primer yang berfungsi sebagai tempat orang tinggal dan melangsungkan kehidupannya. Semula rumah untuk tempat tinggal dibangun sendiri oleh pemiliknya, tetapi seiring kemajuan ekonomi dengan berbagai kesibukannya, orang harus membeli rumah yang dibangun pihak lain, entah perorangan atau perusahaan pengembang[1]. Pada penelitian ini penulis melakukan penelitian pada perumahan wilayah kota Depok yaitu Grand Depok City, Telaga Kahuripan, Maharaja, Sawangan Permai dan Pesona Kayangan dengan menggunakan 6 kriteria yaitu harga, lokasi, KPR, fasilitas, type rumah dan pembayaran awal. Berdasarkan dinas Kependudukan dan Catatan Sipil kota Depok mencatat pertumbuhan penduduk mencapai 6\% setiap tahunnya [2]. Banyaknya orang yang mencari lokasi rumah tinggal di daerah penyangga Ibukota salah satunya kota Depok, Sejak tahun 2012 sampai dengan 2016 ada peningkatan penduduk mencapai 2 juta jiwa dari yang hanya 1,2 juta penduduk [3].

Dalam pemilihan rumah tinggal penulis menggunakan dua perbandingan metode sistem pendukung keputusan yaitu menggunakan metode SAW (Simple Additive Weighting) dan Profile Matching. Sistem pendukung keputusan secara umum didefenisikan sebagai sebuah sistem yang dapat menghasilkan pemecah maupun penanganan masalah. Sistem pendukung keputusan tidak dimaksudkan untuk menggantikan peran pengambil keputusan, tapi untuk membantu dan mendukung pengambil keputusan [4]. Metode SAW dan Profile Matching merupakan metode yang hasil akhirnya berupa perengkingan dari proses perhitungan yang telah dilakukan [5]. Pada metode profile matching dipilih karena metode ini mampu memberikan rekomendasi dengan nilai terdekat, jadi walaupun tidak ada lahan lokasi sesuai persis dengan yang di inginkan developer tapi profile matching akan memberikan rekomendasi pemilihan lahan lokasi dengan profil yang terdekat dengan yang diinginkan developer [6] dan dapat membandingkan antara kriteria existing berupa data tabular yang disajikan berbasis geospasial lengkap dengan informasi yang ditentukan oleh perusahaan/perbankan sehingga diperoleh perbedaan bobot antar kriteria atau disebut gap [7]. Metode Profile Matching mampu mengolah data berdasarkan variabel yang menjadi kriteria dalam proses penilaian prestasi dari kinerja karyawan [8]. Untuk metode SAW dapat dijadikan sebagai suatu sistem pendukung keputusan suatu permasalahan yang terjadi, sehingga keputusan yang diambil dapat memberikan keuntungan maksimal [9].

Berdasarkan dari penelitian sebelumnya keterkaitan dengan penelitian ini adalah menggunakan metode SAW dan Profile Matching dalam pengambil keputusan ini untuk menjelaskan permasalahan, pengumpulan data menjadi informasi dan menentukan alternatif solusi permasalahan dalam pemilihan rumah tinggal diwilayah Kota Depok. 


\section{METODE PENELITIAN}

Pada penelitian ini dilakukan menggunakan perbandingan dua metode sistem pendukung keputusan yaitu Simple Additive Weighting (SAW) dan Profile Matching. Berikut adalah penjabaran dari dua metode tersebut:

\section{A. Metode Simple Additive Weighting (SAW)}

Metode SAW disebut dengan metode penjumlahan terbobot. Konsep dasarnya adalah mencari penjumlahan terbobot dari rating kinerja pada setiap alternatif pada semua atribut [10]. Langkah-langkah penyelesaian metode SAW:

Menentukan kriteria yang akan dijadikan acuan dalam pengambilan keputusan, yaitu $\mathrm{Cj}$.

1. Memberikan nilai setiap alternatif Ai pada setiap kriteria yang sudah ditentukan, dimana nilai tersebut diperoleh berdasarkan nilai crips.

2. Menentukan nilai rating kecocokan setiap alternatif pada setiap kriteria kemudian memodelkannya ke dalam bilangan fuzzy setelah itu konversikan ke bilangan crips.

3. Menentukan bobot preferensi atau tingkat kepentingan (W) setiap kriteria.

4. Membuat matriks keputusan (X) yang dibentuk dari tabel rating kecocokan dari setiap alternatif pada setiap kriteria.

5. Melakukan normalisasi matriks keputusan dengan langkah-langkah menghitung nilai rating kinerja ternomalisasi (rij) dari alternatif Ai pada kriteria $\mathrm{Cj}$.

$$
\begin{aligned}
& \frac{x i j}{M a x x i j} \text { jika } \mathrm{j} \text { adalah atribut keuntungan (benefit) } \\
& R i j=\underset{\frac{M i n X i j}{X i j}}{=} \text { jika j adalah atribut keuntungan (cost)Xij }
\end{aligned}
$$

Diketahui :

Rij = peringkat keadaaan semula Maxij = Nilai maksimum dari setiap baris dan kolom

Minij = Nilai minimum dari setiap baris dan kolom $\mathrm{Xij}=$ Baris dan kolom dari matriks

Keterangan :

Nilai Kriteria untuk keuntungan apabila memberikan keuntungan untuk yang mengambil keputusan, dan sebaliknya terdapat kriteria biaya jika menimbulkan biaya bagi yang mengambil keputusan. Kriteria keuntungan didapat bila nilai dibagi dengan nilai dari setiap kolom, sedangkan untuk kriteria biaya, didapat bila nilai dari setiap kolom dibagi dengan nilai.

6. Hasil dari nilai rating kinerja ternomalisasi (rij) membentuk matrik ternormalisasi (R)

7. Akhir nilai hasil preferensi (Vi) diperoleh dari penjumlahan dari perkalian elemen kerja matrik teromalisasi dengan bobot preferensi (W) yang bersesuaian elemen kolom matrik W). 
INTENSIF, Vol.2 No.2 August 2018

ISSN: 2580-409X (Print) / 2549-6824 (Online)

Website: http//ojs.unpkediri.ac.id/index.php/intens if

$$
\mathrm{VI}=\sum_{j=1}^{n} W j r i j
$$

Keterangan:

$\mathrm{V}_{\mathrm{i}=}$ Rangking untuk setiap alternative

$\mathrm{Wj}=$ Nilai bobot rangking (dari setiap alternatif)

rij=Nilai rating kinerja ternormalisasi

nilai Vi yang lebih besar mengindikasikan bahwa alternative Ai lebih terpilih [10].

\section{B. Metode Profile Matching}

Langkah dan perumusan perhitungan dengan metode profile matching[5] :

1. Pembobotan. Pada tahap ini, akan ditentukan bobot nilai masing-masing aspek dengan menggunakan bobot nilai yang telah ditentukan bagi masing-masing aspek itu sendiri.

2. Pengelompokan Core dan Secondary Factor Setelah menentukan bobot nilai gap kriteria yang dibutuhkan, tiap kriteria dikelompokkan menjadi dua kelompok yaitu core factor dan secondary factor. Core Factor (Faktor Utama) merupakan aspek (kompetensi) yang menonjol/paling dibutuhkan. Untuk menghitung core factor digunakan rumus sebagai berikut:

$$
\begin{gathered}
\text { core factor } \\
N C F=\sum \frac{N C(i, s, p)}{\sum I C} \\
\text { secondary factor } \\
N S F=\sum \frac{N S(i, s, p)}{\sum I S}
\end{gathered}
$$

3. Perhitungan nilai total dengan rumus sebagai berikut :

$$
(\mathrm{x}) \% \operatorname{NCF}(\mathrm{i}, \mathrm{s}, \mathrm{p})+(\mathrm{x}) \% \mathrm{NSF}(\mathrm{i}, \mathrm{s}, \mathrm{p})=\mathrm{N}(\mathrm{i}, \mathrm{s}, \mathrm{p})
$$

4. Perhitungan Penentuan Rangking adalah hasil akhir dari proses Profile Matching dengan rumus sebagai berikut :

$$
\text { Ranking : (x)\% NI + (x)\% Ns+(x)\% Np }
$$


INTENSIF, Vol.2 No.2 August 2018

ISSN: 2580-409X (Print) / 2549-6824 (Online)

Website: http://ojs.unpkediri.ac.id/index.php/intensif

\section{HASIL DAN PEMBAHASAN}

Berikut adalah hasil dari penelitian dengan menggunakan metode SAW dan Profile Matching:

A. Analisa Data

Pada analisis data dalam penggunaan metode SAW dan profile matching dilakukan klasifikasi pembobotan disetiap kriterianya. Dimana dalam pemilihan rumah tinggal ini, diperoleh kriteria-kriteria dan pembobotannya. Kriteria yang digunakan sebagai penilaian seperti pembobotan kriteria harga, lokasi, KPR, fasilitas, type rumah dan pembayaran awal dengan tingkat kepentingan dari setiap kriteria dinilai dengan range 1 sampai dengan 5. Untuk penjabaran pembobotan kriterianya dan nilai tingkat kepentingan sebagai berikut:

Tabel 1. TingKat KePEnTINGAN

\begin{tabular}{cl}
\hline \hline Nilai & Keterangan \\
\hline 1 & Sangat buruk \\
\hline 2 & Buruk \\
\hline 3 & Cukup \\
\hline 4 & Baik \\
\hline 5 & Sangat Baik \\
\hline
\end{tabular}

Pada tabel 1 menjelaskan tingkat kepentingan dari setiap kriteria dengan range penilaian 1 sampai dengan 5.

Tabel 2. PEMBOBOtAN KRITERIA HARGA

\begin{tabular}{ccc}
\hline \hline No & \multicolumn{1}{c}{ Harga } & Bobot \\
\hline 1 & $<$ Rp. 400 Juta & 5 \\
\hline 2 & Rp.800-900 Juta & 2 \\
\hline 3 & Rp.500-700 Juta & 3 \\
\hline 4 & $>$ Rp. 900 Juta & 1 \\
\hline
\end{tabular}

Tabel 2 menjelaskan pembobotan kriteria harga berdasarkan nilai kepentingan pada tabel 1.

Tabel 3. PEMBOBOTAN KRITERIA LOKASI

\begin{tabular}{clc}
\hline \hline No & \multicolumn{1}{c}{ Lokasi } & Bobot \\
\hline 1 & Pusat Kota & 5 \\
\hline 2 & Pedesaan & 4 \\
\hline 3 & Pinggiran Kota & 3 \\
\hline
\end{tabular}

Pada tabel 3 menjelaskan pembobotan kriteria lokasi berdasarkan nilai kepentingan pada tabel 1 dengan pemilihan lokasi berdasarkan pusat kota, pedesaan dan pinggiran kota.

Tabel 4. PEMBOBOtAN KRITERIA KPR

\begin{tabular}{clc}
\hline \hline No & \multicolumn{1}{c}{ KPR } & Bobot \\
\hline 1 & Bank DKI Syariah & 5 \\
\hline 2 & Bank BTN & 3 \\
\hline 3 & Bank Mandiri & 2
\end{tabular}

INTENSIF: Jurnal Ilmiah Penelitian dan Penerapan Teknologi Sistem Informasi 
INTENSIF, Vol.2 No.2 August 2018

ISSN: 2580-409X (Print) / 2549-6824 (Online)

Website: http//ojs.unpkediri.ac.id/index.php/intensif

Pada tabel 4 menjelaskan pembobotan kriteria KPR berdasarkan nilai kepentingan pada tabel 1 berdasarkan KPR pada Bank DKI Syariah, BTN dan Mandiri.

Tabel 5. PEMBOBOtAN KRITERIA FASILITAS

\begin{tabular}{clc}
\hline \hline No & \multicolumn{1}{c}{ Fasilitas } & Bobot \\
\hline 1 & Ada (Playground, kolam renang) & 5 \\
\hline 2 & Tidak Ada & 2 \\
\hline
\end{tabular}

Pada tabel 5 menjelaskan pembobotan kriteria fasilitas berdasarkan nilai kepentingan pada tabel 1 dengan fasilitas playground dan kolam renang.

Tabel 6. PEMBOBOTAN KRITERIA TIPE RUMAH

\begin{tabular}{ccc}
\hline \hline No & Type Rumah & Bobot \\
\hline 1 & Type 36 & 5 \\
\hline 2 & Type 45 & 3 \\
\hline 3 & >Type 45 & 2 \\
\hline
\end{tabular}

Pada tabel 6 menjelaskan pembobotan kriteria type rumah berdasarkan nilai kepentingan pada tabel 1 untuk type rumah yang menjadi pilihan adalah type 36, type 45 dan type $>45$.

Tabel 7. Pembobotan Kriteria Pembayaran Awal

\begin{tabular}{llc}
\hline \hline No & Pembayaran Awal & Bobot \\
\hline 1 & $10 \%$ dari Harga Total & 5 \\
\hline 2 & $>10 \%$ dari Harga Total & 2 \\
\hline
\end{tabular}

Pada tabel 7 menjelaskan pembobotan kriteria pembayaran awal berdasarkan nilai kepentingan pada tabel 1 dimana untuk pembayaran awal sudah ditentukan oleh pengembang. Pada penelitian ini penulis mengambil sampel alternatif lima perumahan yang ada di wilayah kota Depok yaitu: Grand Depok City (A1), Telaga Kahuripan (A2), Maharaja (A3), Sawangan Permai (A4) dan Pesona Kayangan (A5).

\section{B. Metode SAW (Simple Additive Weighting)}

Pada metode ini langkah pertama yang dilakukan adalah menentukan alternatif, kriteria dan pembobotan kriteria yang digunakan sebagai acuan dapat dilihat pada analisis data diatas. Dimana terdapat lima alternatif yaitu A1, A2, A3, A4 dan A5. Kriteria yaitu yang digunakan adalah Harga, Lokasi, KPR, Type Rumah, Fasilitas dan Pembayaran awal. Sebelum melakukan penghitungan dengan algoritma SAW yang dilakukan pertama adalah menentukan kriteria penilaian dengan menentukan nilai kriteria $\mathrm{Cj}$ pada suatu set alternatif $\mathrm{Ai}$, bobot preferensi $(\mathrm{Wj})$ setiap kriteria cj, kemudian melakukan konversi berdasarkan alternatif dan kriteria yang sudah terdata kemudian dihasilkan nilai normalisasi selanjutnya akan dibuat perkalian matriks (preferensi) untuk mendapatkan perangkingan dari semua alternatif. Untuk penjabaran algoritma SAW adalah sebagai berikut: 
INTENSIF, Vol.2 No.2 August 2018

ISSN: 2580-409X (Print) / 2549-6824 (Online)

Website: http://ojs.unpkediri.ac.id/index.php/intensif

Tabel 8. KRITERIA PENILAIAN

\begin{tabular}{cl}
\hline \hline Kriteria & Bobot \\
\hline Harga & $20 \%$ \\
\hline Lokasi & $25 \%$ \\
\hline KPR & $15 \%$ \\
\hline Type Rumah & $12,5 \%$ \\
\hline Fasilitas & $12,5 \%$ \\
\hline Pembayaran Awal & $15 \%$ \\
\hline
\end{tabular}

Pada tabel 8. diatas menjelaskan bobot nilai untuk setiap kriteria yang ada.

Tabel 9. Standar Nilai Algoritma SAW

\begin{tabular}{cl}
\hline \hline Nilai & Keterangan \\
\hline 1 & Sangat rendah \\
\hline 2 & Rendah \\
\hline 3 & Cukup \\
\hline 4 & Tinggi \\
\hline 5 & Sangat Tinggi \\
\hline
\end{tabular}

Tabel 9. dijelaskan standar nilai dari Algoritma SAW, untuk range penilaian 1 sampai dengan 5.

Tabel 10. NiLAi SETELAH DIKONVERSI PADA ALgORITMA SAW

\begin{tabular}{ccccccc}
\hline \hline & & & & Type & & Pembayaran \\
Alternatif & Harga & Lokasi & KPR & Rumah & Fasilitas & Awal \\
\hline A1 & 5 & 5 & 3 & 4 & 4 & 5 \\
\hline A2 & 5 & 5 & 4 & 3 & 4 & 4 \\
\hline A3 & 3 & 3 & 4 & 4 & 3 & 5 \\
\hline A4 & 4 & 5 & 5 & 5 & 5 & 5 \\
\hline A5 & 4 & 4 & 4 & 4 & 5 & 5 \\
\hline
\end{tabular}

Tabel 10. Diatas menjelaskan nilai setelah dikonversi berdasarkan alternatif dan kriteria yang sudah terdata. Setelah bobot alternatif telah disesuaikan dengan nilai kecocokan maka masuk ketahap normalisasi dengan rumus (1). Dapat dilihat pada tabel 11.

Tabel 11. HASIL NORM ALISASI DENGAN ALGORITMA SAW

\begin{tabular}{ccccccc}
\hline \hline & & & \multicolumn{3}{c}{ Type } & Pembayaran \\
Alternatif & Harga & Lokasi & KPR & Rumah & Fasilitas & Awal \\
\hline A1 & 0,60 & 1,00 & 1,00 & 0,80 & 0,80 & 0,80 \\
\hline A2 & 0,60 & 1,00 & 0,75 & 0,60 & 0,80 & 1,00 \\
\hline A3 & 1,00 & 0,60 & 0,75 & 0,80 & 0,60 & 0,80 \\
\hline A4 & 0,75 & 1,00 & 0,60 & 1,00 & 1,00 & 0,80 \\
\hline A5 & 0,75 & 0,80 & 0,75 & 0,80 & 1,00 & 0,80 \\
\hline
\end{tabular}

Setelah didapat hasil dari normalisasi, maka selanjutnya akan dibuat perkalian matriks (preferensi) untuk mendapatkan perangkingan dari semua alternatif dan dapat dilihat pada tabel 12 sebagai berikut: 
INTENSIF, Vol.2 No.2 August 2018

ISSN: 2580-409X (Print) / 2549-6824 (Online)

Website: http//ojs.unpkediri.ac.id/index.php/intensif

Tabel 12. NILAI PREFERENSI DAN RANK

\begin{tabular}{ccc}
\hline \hline Alternatif & Hasil & Rank \\
\hline A1 & 0,72 & 2 \\
\hline A2 & 0,66 & 4 \\
\hline A3 & 0,64 & 5 \\
\hline A4 & 0,74 & 1 \\
\hline A5 & 0,69 & 3 \\
\hline
\end{tabular}

Berdasarkan proses metode SAW maka dapat disimpulkan bahwa yang memiliki nilai tertinggi adalah kode alternatif (A4) dengan nilai 0,74 yaitu Sawangan Permai ditetapkan sebagai tempat tinggal yang pertama diminati berdasarkan perhitungan algoritma SAW.

C. Metode Profile Matching

Pada metode ini untuk bobot nilai dari tiap sub kriteria telah ditentukan pada tahap analisa data diatas (tabel $2 \mathrm{~s} / \mathrm{d}$ tabel 7). Langkah kedua yaitu penentuan nilai profil pencapaian akan dengan range nilai antara 1 sampai 5. Dari nilai-nilai tersebut akan dilakukan proses perhitungan gap antara nilai profil mitra dengan nilai profil pencapaian. Adapun profil pencapaian yang telah ditentukan adalah dapat dilihat pada tabel 13 sebagai berikut:

Tabel 13. NILAI PROFIL PENCAPAIAN

\begin{tabular}{ccc}
\hline \hline Kriteria & Profil Pencapaian & Jenis \\
\hline Harga & 3 & Core Factor \\
\hline Lokasi & 5 & Core Factor \\
\hline KPR & 3 & Core Factor \\
\hline Type Rumah & 5 & Secondary Factor \\
\hline Fasilitas & 5 & Secondary Factor \\
\hline Pembayaran Awal & 4 & Core Factor \\
\hline
\end{tabular}

Setelah menentukan nilai profil pencapaian, maka dapat dilakukan perhitungan Gap dengan rumus:

$$
\text { GAP }=\text { Profil Mitra }- \text { Profil Pencapaian }
$$

Maka hasil perhitungan gap dapat dilihat pada tabel 14 sebagai berikut: 
INTENSIF, Vol.2 No.2 August 2018

ISSN: 2580-409X (Print) / 2549-6824 (Online)

Website: http://ojs.unpkediri.ac.id/index.php/intensif

Tabel 14. GAP KOMPETENSI

\begin{tabular}{|c|c|c|c|c|c|c|c|c|}
\hline \multirow[b]{2}{*}{ Alternatif } & \multicolumn{6}{|c|}{ Krtite ria } & & \\
\hline & Harga & Lokasi & KPR & Type Rumah & Fasilitas & $\begin{array}{c}\text { Pembayaran } \\
\text { Awal }\end{array}$ & & \\
\hline A1 & 5 & 5 & 3 & 4 & 4 & 5 & \multirow{5}{*}{\multicolumn{2}{|c|}{$\frac{\bar{\pi}}{\overline{7}}$}} \\
\hline $\mathrm{A} 2$ & 5 & 5 & 4 & 3 & 4 & 4 & & \\
\hline A3 & 3 & 3 & 4 & 4 & 3 & 5 & & \\
\hline A4 & 4 & 5 & 5 & 5 & 5 & 5 & & \\
\hline A5 & 4 & 4 & 4 & 4 & 5 & 5 & & \\
\hline $\begin{array}{c}\text { Nilai } \\
\text { Pencapaian }\end{array}$ & 3 & 5 & 3 & 5 & 5 & 4 & $(-)$ & $(+)$ \\
\hline A1 & 2 & 0 & 0 & -1 & -1 & 1 & 1 & 0 \\
\hline $\mathrm{A} 2$ & 2 & 0 & 1 & -2 & -1 & 0 & 0 & 0 \\
\hline A3 & 0 & -2 & 1 & -1 & -2 & 1 & -3 & 0 \\
\hline A4 & 1 & 0 & 2 & 0 & 0 & 1 & 4 & 0 \\
\hline A5 & 1 & -1 & 1 & -1 & 0 & 1 & 1 & 0 \\
\hline
\end{tabular}

Setelah diperoleh gap dari masing-masing alternatif, setiap profil calon mitra di beri bobot nilai dengan patokan tabel bobot nilai gap. Pembobotan yang digunakan pada penelitian ini dapat dilihat pada tabel 15 dibawah ini:

Tabel 15. Вовот NILAI

\begin{tabular}{llll}
\hline \hline No & Selisih & $\begin{array}{l}\text { Bobot } \\
\text { Nilai }\end{array}$ & Keterangan \\
\hline 1 & 0 & 5 & Tidak ada selisih (kompetensi sesuai dengan yang dibutuhkan) \\
\hline 2 & 1 & 4,5 & Kompetensi individu kelebihan 1 tingkat/level \\
\hline 3 & -1 & 4 & Kompetensi individu kekurangan 1 tingkat/level \\
\hline 4 & 2 & 3,5 & Kompetensi individu kelebihan 2 tingkat/level \\
\hline 5 & -2 & 3 & Kompetensi individu kekurangan 2 tingkat/level \\
\hline 6 & 3 & 2,5 & Kompetensi individu kelebihan 3 tingkat/level \\
\hline 7 & -3 & 2 & Kompetensi individu kekurangan 3 tingkat/level \\
\hline 8 & 4 & 1,5 & Kompetensi individu kelebihan 4 tingkat/level \\
\hline 9 & -4 & 1 & Kompetensi individu Kekurangan 4 tingkat/level \\
\hline
\end{tabular}

Dengan demikian bobot nilai gap dari tiap alternatif dapat dilihat pada tabel 16 sebagai berikut:

Tabel 16. РемвовотAN NilAi GAP

\begin{tabular}{ccccccc}
\hline \hline & \multicolumn{6}{c}{ Kriteria } \\
\cline { 2 - 7 } Alternatif & Harga & Lokasi & KPR & Type Rumah & Fasilitas & Pembayaran Awal \\
\hline A1 & 3,5 & 5 & 5 & 4 & 4 & 4,5 \\
\hline A2 & 3,5 & 5 & 4,5 & 3 & 4 & 5 \\
\hline A3 & 5 & 3 & 4,5 & 4 & 3 & 4,5 \\
\hline A4 & 4,5 & 5 & 3,5 & 5 & 5 & 4,5 \\
\hline A5 & 4,5 & 4 & 4,5 & 4 & 5 & 4,5 \\
\hline
\end{tabular}


INTENSIF, Vol.2 No.2 August 2018

ISSN: 2580-409X (Print) / 2549-6824 (Online)

Website: http//ojs.unpkediri.ac.id/index.php/intensif

Langkah ketiga adalah melakukan perhitungan berdasarkan pengelompkan core factor dan secondaryfactor. Berdasarkan tabel 13, yang merupakan core factor adalah kriteria harga, lokasi, KPR dan Pembayaran awal. Sedangkan kriteria secondary factor adalah type rumah dan fasilitas. Berdasarkan tabel 16 maka dilakukan perhitungan dengan rumus (3) dan (4) untuk diperoleh nilai rata-rata Core Factor (NCF) dan rata-rata Secondary Factor (NSF). Hasilnya dapat dilihat pada tabel 17 sebagai berikut:

Tabel 17. NILAI RATA-RATA NCF DAN NSF

\begin{tabular}{ccc}
\hline \hline Alternatif & NCF & NSF \\
\hline $\mathrm{A} 1$ & 14,63 & 6,00 \\
\hline $\mathrm{A} 2$ & 14,25 & 5,00 \\
\hline $\mathrm{A} 3$ & 13,63 & 5,50 \\
\hline $\mathrm{A} 4$ & 14,13 & 7,50 \\
\hline $\mathrm{A} 5$ & 14,13 & 6,50 \\
\hline
\end{tabular}

Setelah diperoleh nilai NCF dan NSF, langkah selanjutnya nilai total berdasarkan persentase dari core dan secondary yang diperkirakan berpengaruh terhadap kinerja tiap-tiap profil. Adapun presentase yang dimasukkan adalah untuk core factor $60 \%$ dan secondary factor $40 \%$. Sihingga nilai total yang diperoleh berdasarkan rumus (5) dan dapat dilihat pada tabel 18 sebagai berikut:

Tabel 18. Perhitungan Nilai Total

\begin{tabular}{cccc}
\hline \hline Alternatif & NCF & NSF & Nilai Total \\
\hline A1 & 14,63 & 6,00 & 11,18 \\
\hline A2 & 14,25 & 5,00 & 10,55 \\
\hline A3 & 13,63 & 5,50 & 10,38 \\
\hline A4 & 14,13 & 7,50 & 11,48 \\
\hline A5 & 14,13 & 6,50 & 11,08 \\
\hline
\end{tabular}

Langkah terakhir setelah diperoleh nilai totol, maka dilakukan proses perangkingan dengan mengurutkan dari nilai paling besar sampai dengan terkecil. Dimana nilai terbesar merupakan alternatif terpilih dan hasilnya ada pada tabel 19.

Tabel 19. PerengKingan Alternatif

\begin{tabular}{ccc}
\hline \hline Alternatif & Nilai Total & Rank \\
\hline A1 & 11,18 & 2 \\
\hline A2 & 10,55 & 4 \\
\hline A3 & 10,38 & 5 \\
\hline A4 & 11,48 & 1 \\
\hline A5 & 11,08 & 3 \\
\hline
\end{tabular}


Dari hasil perengkingan pada tabel 19 , hasilnya adalah A4 = Sawangan Permai merupakan alternatif terpilih berdasarkan metode Profile Matching sebagai pemilihan rumah yang berada dikota Depok.

D. Hasil Perbandingan metode SAW dan Profil Matching

Berdasarkan perhitungan dengan metode SAW dan Profile Matching maka diperoleh hasil perengkingan dari kedua metode tersebut pada tabel 20 sebagai berikut:

Tabel 20. Hasil Perbandingan Metode SAW dan Profile Matching

\begin{tabular}{cccccc}
\hline \hline \multicolumn{3}{c}{ Metode SAW } & \multicolumn{4}{c}{ Metode Profile Matching } \\
\hline Alternatif & Nilai Total & Rank & Alternatif & Nilai Total & Rank \\
\hline A1 & 0,72 & 2 & A1 & 11,18 & 2 \\
\hline A2 & 0,66 & 4 & A2 & 10,55 & 4 \\
\hline A3 & 0,64 & 5 & A3 & 10,38 & 5 \\
\hline A4 & 0,74 & 1 & A4 & 11,48 & 1 \\
\hline A5 & 0,69 & 3 & A5 & 11,08 & 3 \\
\hline
\end{tabular}

Perbandingan metode SAW dan Profile matching menghasilkan perengkingan yang sama dengan alternatif ke 4 yaitu Sawangan Permai menjadi pilihan utama pada perhitungannya, untuk metode SAW dengan nilai 0,74 dan profile matching 11,48. Sehingga penilaian dengan metode SAW muapun Profile Matching dapat digunakan dalam pengambil keputusan dalam pemilihan rumah diwilayah kota Depok dengan kriteria yang ada.

\section{KESIMPULAN DAN SARAN}

Kesimpulan dari penelitian yang sudah dilakukan adalah dengan menggunakan dua metode SAW dan Profile Matching pada pemilihan rumah tinggal dapat menunjukan hasil akhir yang sama berdasarkan kriteria dan data yang sama. Berdasarkan pada metode SAW alternatif terpilih adalah A4 dengan nama Sawangan Permai, hasil yang sama pada metode Profile Matching. Metode SAW dan Profile Matching merupakan metode yang hasil akhirnya berupa perengkingan dari proses perhitungan yang telah dilakukan. Jadi, kedua metode ini dapat diterapkan dalam pemilihan rumah tinggal untuk membantu pengambilan keputusan, karena kedua metode ini menghasilkan alternatif terbaik yang sama. 
INTENSIF, Vol.2 No.2 August 2018

ISSN: 2580-409X (Print) / 2549-6824 (Online)

Website: http:/ojs.unpkediri.ac.id/index.php/intensif

\section{DAFTAR PUSTAKA}

[1] T. R. Adianto, Z. Arifin, and D. M. Khairina, "Sistem Pendukung Keputusan Pemilihan Rumah Tinggal Di Perumahan Menggunakan Metode Simple Additive Weighting (Saw) (Studi Kasus: Kota Samarinda),” Pros. Semin. Ilmu Komput. dan Teknol. Inf., vol. 2, no. 1, pp. 197-201, 2017.

[2] R. R. Purnama, "Pertumbuhan Penduduk Depok 6\% Setiap Tahun," 2014. .

[3] Y. Petriella, "PENYANGGA IBU KOTA : Menyiasati Perkembangan Depok," 2017.

[4] H. Manao, B. Nadeak, and T. Zebua, "Sistem Pendukung Keputusan Pemilihan Perumahan Dengan Metode Simple Additive Weighting (Saw)," Media Inform. Budi Darma, vol. 1, no. 2, pp. 49-53, 2017.

[5] T. Y. Akhirina, "Komparasi Metode Simple Additive Weighting dan Profile Matching pada Pemilihan Mitra Jasa Pengiriman Barang,” J. Edukasi dan Penelit. Inform., vol. 2, no. 1, pp. 27-33, 2016.

[6] M. Raihan and S. Abidah, "Penerapan Metode Profile Matching Pada Proses Pemilihan Lokasi Perumahan,” pp. 827-836.

[7] C. Miftilasari, H. Nasution, and M. A. Irwansyah, "Pemilihan Kpr Perumahan Dengan."

[8] Sunarti, "Sistem Pendukung Keputusan Penilaian Kualitas Kinerja Karyawan Menggunakan Profile Matching ( Studi Kasus : Apartemen Senayan Jakarta )," Techno.com, vol. 17, no. 1, pp. 103-110, 2018.

[9] N. C. Resti, "Penerapan Metode Simple Additive Weighting (SAW) pada Sistem Pendukung Keputusan Pemilihan Lokasi untuk Cabang Baru Toko Pakan UD. Indo Multi Fish," Intensif, vol. 1, no. 2, pp. 102-107, 2017.

[10] D. Nofriansyah, Konsep Data Mining Vs Sistem Pendukung Keputusan. Yogyakarta: Deepublish, 2015. 